\title{
An Alternative Three-phase Transmission Lines Model in Phase Domain
}

\author{
C. G. Carvalho ${ }^{1}$, S. Kurokawa ${ }^{1}$, J. Pissolato ${ }^{2}$ \\ ${ }^{1}$ Universidade Estadual Paulista (Unesp), Electrical Engineering Department, Ilha Solteira, Brazil \\ ${ }^{2}$ Universidade Estadual de Campinas (Unicamp), Electrical Engineering Department, Campinas, Brazil \\ Email: carol.gcarvalho@hotmail.com
}

Received 2013

\begin{abstract}
The objective of this paper is to show an alternative model of a non-transposed three-phase transmission line with a vertical symmetry plane in phase domain. Due the line physical characteristics, it can be represented by a system consisting of a single-phase and a two-phase line. In this system, the equations describing the behavior of the values in single-phase line terminals are known, while the equations for two-phase line to be obtained. Using a transformation matrix written explicitly according to three-phase line parameters, it is possible to obtain the currents and voltages in phase domain of two-phase line. Then, modal values of three-phase line are converted into phase domain and thus obtain the analytical model for this line. To verify the performance of this model, it was used to simulate the energization of a $440 \mathrm{kV}$ three-phase line and the results were compared to results obtained using a classical model.
\end{abstract}

Keywords: Transmission Lines; Frequency Dependence; Modal Representation; Transformation Matrix; Newton-Raphson; Phase Domain

\section{Introduction}

It is known that methods of electromagnetic transient analysis in power systems can consider transmission line models written in phase domain or in modal domain [1].

If the transmission line is represented by its modes, the line operations are effectuated in modal domain and after that transformed back to phase domain. This way a transmission line with $\mathrm{n}$ phases can be decoupled in its $\mathrm{n}$ exact modes and each mode can be represented as being a single-phase line transmission.

In multiphase lines, transformation phase-mode-phase is done by a modal transformation matrix [2]. Because per unit length longitudinal impedance matrix and shunt admittance matrix are frequency dependence, modal transformation matrices are frequency dependence too. Therefore the modal transformation matrices are usually obtained by numerical methods that not permitting the development of an analytical model this line for.

Thereby, if it is obtained explicitly a function that lists the elements of the transformation matrix with the line parameters, it is possible to develop a direct model in phase's domain of a transmission line, depending only of its parameters.

Advantages principal of a transmission line model developed directly in phase domain are: the model developed in phases domain, the currents and voltages can be obtained in any situation of analysis line (e.g. in analysis line considering the line in phase-ground andlor phasephase short circuit), which cannot be easily done in modal model; all terms present in equations that represent this model are functions only of $[\mathrm{Z}]$ and $[\mathrm{Y}]$ parameters, which will allow representing the phases in time domain.

This paper proposes to show the development of a model for a non-transposed three-phase transmission line with a vertical symmetry plane in phase modal.

\section{Alternative Model for Three-Phase Transmission lines}

A transmission lines with phases are characterized by it's per unit length longitudinal impedance, matrix [Z], and shunt admittance, matrix [Y]. If this line is represented in modal domain, has the following relationship [2]:

$$
\begin{aligned}
& {\left[Z_{m}\right]=\left[T_{I}\right]^{t}[Z]\left[T_{I}\right]} \\
& {\left[Y_{m}\right]=\left[T_{I}\right]^{-1}[Y]\left[T_{I}\right]^{-t}}
\end{aligned}
$$

In (1) and (2), the matrices $\left[\mathrm{Z}_{\mathrm{m}}\right]$ and $\left[\mathrm{Y}_{\mathrm{m}}\right]$ are per unit length impedance and admittance modal matrices, respectively. Matrices $\left[\mathrm{Z}_{\mathrm{m}}\right]$ and $\left[\mathrm{Y}_{\mathrm{m}}\right]$ are diagonal matrices and $\left[\mathrm{T}_{\mathrm{I}}\right]$ is a transformation matrix whose columns are the eigenvectors associated with the eigenvalues of the product $[\mathrm{Y}][\mathrm{Z}]$. In (1) $\left[\mathrm{T}_{\mathrm{I}}\right]^{\mathrm{t}}$ is the transpose of $\left[\mathrm{T}_{\mathrm{I}}\right]$ and in (2) $\left[T_{I}\right]^{-t}$ is the inverse of $\left[T_{I}\right]^{t}$. 
In modal domain, a multiphase line with $\mathrm{n}$ phases is represented by their $n$ propagation modes which behave as $\mathrm{n}$ decoupled single-phase lines. Figure 1 shows a generic mode of the multiphase transmission line.

In Figure 1, $\mathrm{E}_{\mathrm{A}}$ e $\mathrm{E}_{\mathrm{B}}$ are, respectively, modal voltages at $A$ and $B$ terminals, respectively, while $I_{m A}$ and $I_{m B}$ are, respectively, modal currents at $\mathrm{A}$ and $\mathrm{B}$ terminals, written in modal domain.

The relationship between phase and modal values are obtained as follows [3]:

$$
\begin{aligned}
& E_{A}=E_{B} \cosh (\gamma d)-\mathrm{I}_{\mathrm{mB}} Z_{C} \sinh (\gamma d) \\
& I_{m A}=-\mathrm{I}_{\mathrm{mB}} \cosh (\gamma d)+\frac{E_{B}}{Z_{C}} \sinh (\gamma d)
\end{aligned}
$$

In (3) and (4), the terms $\gamma$ and $Z_{C}$ are, respectively, modal propagation function and modal characteristic impedance $[4,5]$.

Considering a generic three-phase transmission line, this line will be represented in modal domain by its three propagation modes. Thus, applying (3) and (4) for each mode, have the following voltage and current vectors in modal domain:

$$
\begin{aligned}
& {\left[E_{A}\right]=[A]\left[E_{B}\right]-[\mathrm{B}]\left[\mathrm{I}_{\mathrm{mB}}\right]} \\
& {\left[I_{m A}\right]=[\mathrm{C}]\left[\mathrm{E}_{\mathrm{B}}\right]-[D]\left[I_{m B}\right]}
\end{aligned}
$$

In (5) e (6), the matrix [D] is equal to the matrix [A] and the matrices $[\mathrm{A}],[\mathrm{B}]$ and $[\mathrm{C}]$ are written as:

$$
\begin{aligned}
& {[A]=\left[\begin{array}{ccc}
\cosh \left(\gamma_{m 1} d\right) & 0 & 0 \\
0 & \cosh \left(\gamma_{m 2} d\right) & 0 \\
0 & 0 & \cosh \left(\gamma_{m 3} d\right)
\end{array}\right]} \\
& {[B]=\left[\begin{array}{cccc}
Z_{C m 1} \sinh \left(\gamma_{m 1} d\right) & 0 & 0 \\
0 & Z_{C m 2} & \sinh \left(\gamma_{m 2} d\right) & 0 \\
0 & 0 & Z_{C m 3} & \sinh \left(\gamma_{m 3} d\right)
\end{array}\right]} \\
& {[C]=\left[\begin{array}{ccc}
\frac{1}{Z_{C m 1}} \sinh \left(\gamma_{m 1} d\right) & 0 & 0 \\
0 & \frac{1}{Z_{C m 2}} \sinh \left(\gamma_{m 2} d\right) & 0 \\
0 & 0 & \frac{1}{Z_{C m 3}} \sinh \left(\gamma_{m 3} d\right)
\end{array}\right]}
\end{aligned}
$$

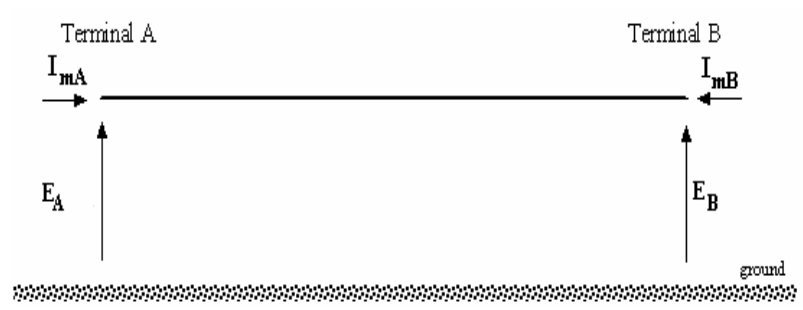

Figure 1. A generic mode multiphase transmission line.
It is known that phase and mode values so satisfy the following relationships [3]:

$$
\begin{array}{r}
{[E]=\left[T_{I}\right]^{t}[V]} \\
{\left[I_{m}\right]=\left[T_{I}\right]^{-1}[I]}
\end{array}
$$

In (10), the vectors [V] and [E], are transversal voltages written in phase and modal domain, respectively, and in (11), the vectors $[\mathrm{I}]$ and $\left[\mathrm{I}_{\mathrm{m}}\right]$, are the longitudinal currents written in phase and modal domain, respectively.

Replacing (10) and (11) in (5) and (6), and making the appropriate mathematical manipulations, are obtained:

$$
\begin{aligned}
& {\left[V_{A}\right]=\left[T_{I}\right]^{-t}[A]\left[T_{I}\right]^{t}\left[V_{B}\right]-\left[T_{I}\right]^{-t}[B]\left[T_{I}\right]^{-1}\left[I_{B}\right]} \\
& {\left[I_{A}\right]=\left[T_{I}\right][C]\left[T_{I}\right]^{t}\left[V_{B}\right]-\left[T_{I}\right][D]\left[T_{I}\right]^{-1}\left[I_{B}\right]}
\end{aligned}
$$

Equations (12) and (13) show the relationships between phase values at $\mathrm{A}$ and $\mathrm{B}$ terminals of a generic threephase line. The vectors $\left[\mathrm{V}_{\mathrm{A}}\right]$ and $\left[\mathrm{V}_{\mathrm{B}}\right]$ contain the phase voltages in $A$ and $B$ terminals, respectively, while $\left[\mathrm{I}_{\mathrm{A}}\right]$ and $\left[\mathrm{I}_{\mathrm{B}}\right]$ contain the phase currents in $\mathrm{A}$ and $\mathrm{B}$ terminals, respectively. Matrices $\left[\mathrm{T}_{\mathrm{I}}\right],[\mathrm{A}],[\mathrm{B}],[\mathrm{C}]$ and $[\mathrm{D}]$ are obtained according to three-phase line parameters.

Equations (12) and (13) represent an equation model that possibility to obtain the phase values for a generic three-phase transmission line. However, the development of this model is only possible if the matrix $\left[\mathrm{T}_{\mathrm{I}}\right]$ is obtained analytically.

It is known that $\left[\mathrm{T}_{\mathrm{I}}\right]$ columns are eigenvectors associated to the product $[\mathrm{Y}][\mathrm{Z}][2]$. Therefore, it is possible to obtain explicitly a function that represents the elements of each column of the matrix $\left[\mathrm{T}_{\mathrm{I}}\right]$ according to the three-phase line parameters. In this case, to get the elements of the matrix $\left[\mathrm{T}_{\mathrm{I}}\right]$ is necessary, first, calculate the eigenvalues corresponding to the product $[\mathrm{Y}][\mathrm{Z}]$ through [2].

However, for a generic three-phase transmission line, the obtaining these eigenvalues depends on the polynomial solution of degree 3, which is not easily found.

A solution in this case is to consider a non-transposed three-phase transmission line with a vertical symmetry plane. This line can be represented by a system consisting of a single-phase and two-phase line [6]. Then the three-phase line is separated in its propagation modes by using two modal transformation matrices: the first is the Clarke's matrix [7]; the second is an adequate modal transformation matrix whose elements are frequency dependences $[2,6]$.

This way, to represent a three-phase line directly in phase domain, using (12) and (13), it is need to obtain, analytically, the polynomial solution of degree 2 . Therefore, as well as in single-phase line, the currents and voltages of a three-phase line are obtained directly in the phase domain.

Figure 2 shows a non-transposed three-phase trans- 
mission line with a vertical symmetry plane.

For this line, the longitudinal impedance $[\mathrm{Z}]$ and transverse admittance [Y] are written as [7]:

$$
\begin{aligned}
& {[Z]=\left[\begin{array}{l}
z_{11} z_{12} z_{12} \\
Z_{12} z_{22} z_{23} \\
Z_{12} z_{23} z_{22}
\end{array}\right]} \\
& {[Y]=\left[\begin{array}{l}
y_{11} y_{12} y_{12} \\
y_{12} y_{22} y_{23} \\
y_{12} y_{23} y_{22}
\end{array}\right]}
\end{aligned}
$$

The line in Figure 2 can be represented as a system consisting by a single-phase line and two-phase line. In this representation, the three-phase line can be decoupled into exact modes by using two transformation matrices [6]. Initially, Clarke's matrix is used for decoupling the line in their quasi-modes $\alpha$ and 0 and its exact mode $\beta$ and, after that, an adequate modal transformation matrix decouples the quasi-modes $\alpha$ and 0 into exact mode.

Figure 3 shows a schematic representation of the modal decomposition process by using two transformation matrices.

If in (1) and (2) the transformation matrix $\left[\mathrm{T}_{\mathrm{I}}\right]$ is substituted by Clarke's matrix, the impedance and admittance, in this case, are written, respectively, as being:

$$
\begin{aligned}
& {\left[Z_{\alpha \beta 0}\right]=\left[T_{\text {clarke }}\right]^{t}[Z]\left[T_{\text {clarke }}\right]} \\
& {\left[Y_{\alpha \beta 0}\right]=\left[T_{\text {clarke }}\right]^{-1}[Y]\left[T_{\text {clarke }}\right]^{-t}}
\end{aligned}
$$

Considering the line parameters, equations (14) and (15), the matrices $\left[\mathrm{Z}_{\alpha \beta 0}\right]$ and $\left[\mathrm{Y}_{\alpha \beta 0}\right]$, are rewritten, respectively, as $[6,7]$ :

$$
\left[Z_{\alpha \beta 0}\right]=\left[\begin{array}{ccc}
\frac{1}{3}\left(2 z_{11}-4 z_{12}+z_{22}+z_{23}\right) & 0 & \frac{\sqrt{2}}{3}\left(z_{11}+z_{12}-z_{22}-z_{23}\right) \\
0 & z_{22}-z_{23} & 0 \\
\frac{\sqrt{2}}{3}\left(z_{11}+z_{12}-z_{22}-z_{23}\right) & 0 & \frac{1}{3}\left(z_{11}+4 z_{12}\right)+\frac{2}{3}\left(z_{22}+z_{23}\right)
\end{array}\right]
$$

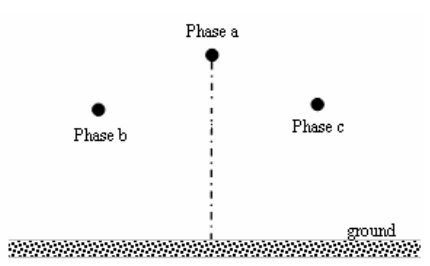

Figure 2. Non-transposed three-phase transmission line with a vertical symmetry plane.

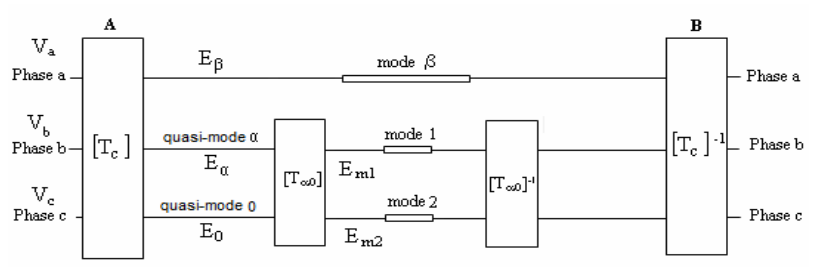

Figure 3. Modal representation by using two transformation matrices.

$$
\left[Y_{\alpha \beta 0}\right]=\left[\begin{array}{ccc}
\frac{1}{3}\left(2 y_{11}-4 y_{12}+y_{22}+y_{23}\right) & 0 & \frac{\sqrt{2}}{3}\left(y_{11}+y_{12}-y_{22}-y_{23}\right) \\
0 & y_{22}-y_{23} & 0 \\
\frac{\sqrt{2}}{3}\left(y_{11}+y_{12}-y_{22}-y_{23}\right) & 0 & \frac{1}{3}\left(y_{11}+4 y_{12}\right)+\frac{2}{3}\left(y_{22}+y_{23}\right)
\end{array}\right]
$$

In (16) and (17), it is verified that the line shown in Figure 2 can be represented as a single-phase and a twophase line and there is not coupling between them [6].

If $\beta$ component is excluded in (18) and (19), are obtained the longitudinal impedance $\left[Z_{\alpha 0}\right]$ and transversal admittance $\left[\mathrm{Y}_{\alpha 0}\right]$ are given by:

$$
\left[Z_{\alpha 0}\right]=\left[\begin{array}{l}
\frac{1}{3}\left(2 z_{11}-4 z_{12}+z_{22}+z_{23}\right) \frac{\sqrt{2}}{3}\left(z_{11}+z_{12}-z_{22}-z_{23}\right) \\
\frac{\sqrt{2}}{3}\left(z_{11}+z_{12}-z_{22}-z_{23}\right) \frac{1}{3}\left(z_{11}+4 z_{12}\right)+\frac{2}{3}\left(z_{22}+z_{23}\right)
\end{array}\right]
$$

$$
\left[Y_{\alpha 0}\right]=\left[\begin{array}{l}
\frac{1}{3}\left(2 y_{11}-4 y_{12}+y_{22}+y_{23}\right) \frac{\sqrt{2}}{3}\left(y_{11}+y_{12}-y_{22}-y_{23}\right) \\
\frac{\sqrt{2}}{3}\left(y_{11}+y_{12}-y_{22}-y_{23}\right) \frac{1}{3}\left(y_{11}+4 y_{12}\right)+\frac{2}{3}\left(y_{22}+y_{23}\right)
\end{array}\right]
$$

These matrices represent a two-phase line without a vertical symmetry plane [6].

In (20), impedance matrix elements are written as:

$$
\begin{aligned}
& Z_{\alpha}=\frac{1}{3}\left(2 z_{11}-4 z_{12}+z_{22}+z_{23}\right) \\
& Z_{\alpha 0}=\frac{\sqrt{2}}{3}\left(z_{11}+z_{12}-z_{22}-z_{23}\right) \\
& Z_{0}=\frac{1}{3}\left(z_{11}+4 z_{12}\right)+\frac{2}{3}\left(z_{22}+z_{23}\right)
\end{aligned}
$$

In (21), admittance matrix elements $\left[\mathrm{Y}_{\alpha 0}\right]$ are written as:

$$
\begin{aligned}
& Y_{\alpha}=\frac{1}{3}\left(2 y_{11}-4 y_{12}+y_{22}+y_{23}\right) \\
& Y_{\alpha 0}=\frac{\sqrt{2}}{3}\left(y_{11}+y_{12}-y_{22}-y_{23}\right) \\
& Y_{0}=\frac{1}{3}\left(y_{11}+4 y_{12}\right)+\frac{2}{3}\left(y_{22}+y_{23}\right)
\end{aligned}
$$

In (22)-(27) all elements are written only according to longitudinal and shunt three-phase line parameters.

In Figure 3, a modal decomposition of the two-phase line is done by using modal transformation matrix $\left[\mathrm{T}_{\alpha 0}\right]$, which diagonalizes the $\left[\mathrm{Y}_{\alpha 0}\right]\left[\mathrm{Z}_{\alpha 0}\right][2]$. Immediately, it can be obtained a relationship between the elements of each column of $\left[\mathrm{T}_{\alpha 0}\right]$ and the three-phase line parameters.

In this case, eigenvalues are obtained by the solution of a polynomial of degree 2 , whose roots are written as: 
$\lambda_{1}=\frac{\left(S_{11}+S_{22}\right)+\sqrt{\left.S_{11}^{2}+S_{22}^{2}-2 S_{11} S_{22}+4 S_{12} S_{21}\right)}}{2}$

$\lambda_{2}=\frac{\left(S_{11}+S_{22}\right)-\sqrt{\left.S_{11}^{2}+S_{22}^{2}-2 S_{11} S_{22}+4 S_{12} S_{21}\right)}}{2}$

In (28) and (29), $\mathrm{S}_{11}, \mathrm{~S}_{12}, \mathrm{~S}_{21}$ and $\mathrm{S}_{22}$ are the elements of the matrix $[\mathrm{S}]$ obtained by calculating the product $\left[\mathrm{Y}_{\alpha 0}\right]\left[\mathrm{Z}_{\alpha 0}\right]$ :

$$
[S]=\left[\begin{array}{c}
Z_{\alpha} Y_{\alpha}+Z_{\alpha 0} Y_{\alpha 0} Z_{\alpha 0} Y_{\alpha}+Z_{0} Y_{\alpha 0} \\
Z_{\alpha} Y_{\alpha 0}+Z_{\alpha 0} Y_{0} Z_{\alpha 0} Y_{\alpha 0}+Z_{0} Y_{0}
\end{array}\right]
$$

Therefore, $\left[\mathrm{T}_{\alpha 0}\right]$ can be written as:

$$
\left[T_{\alpha 0}\right]=\left[\begin{array}{cc}
-\frac{S_{12}}{\sqrt{\left(S_{11}-\lambda_{1}\right)^{2}+S_{12}^{2}}}-\frac{S_{12}}{\sqrt{\left(S_{11}-\lambda_{2}\right)^{2}+S_{12}^{2}}} \\
\frac{S_{11}-\lambda_{1}}{\sqrt{\left(S_{11}-\lambda_{1}\right)^{2}+S_{12}^{2}}}-\frac{S_{11}-\lambda_{2}}{\sqrt{\left(S_{11}-\lambda_{2}\right)^{2}+S_{12}^{2}}}
\end{array}\right]
$$

Considering the expression (31), can be say that $\left[\mathrm{T}_{\alpha 0}\right]$ is writing analytically according to three-phase line parameters since the elements of the matrix [S] are

writing in terms these parameters.

Obtained $\left[\mathrm{T}_{0.0}\right]$ can be established an explicit relationship between two-phase line values and three-phase line parameters. Thereby, are obtained the currents and voltage phases of the two-phase line written according to only three-phase line parameters (Figure 2).

Verifies in Figure 3 that $\beta$ component is an exact mode of three-phase line. Thus, the currents and voltages in this mode are obtained from the equations (3) and (4). Obtained the values in $\alpha, \beta$ and 0 components, the next step is the conversion of these values to domain phases. Process result is a series of equations that allows to obtain currents and voltages phase of the three-phase line. These equations represent a direct model developed in phase domain of three-phase line in Figure 2.

Considering the matrix $\left[\mathrm{T}_{\alpha 0}\right]$ obtained in (31), the equations (12) and (13) are rewritten as:

$$
\begin{aligned}
& {\left[V_{A}\right]=\left[N_{1}\right]\left[V_{B}\right]-\left[N_{2}\right]\left[I_{f B}\right]} \\
& {\left[I_{A}\right]=\left[N_{3}\right]\left[I_{f B}\right]-\left[N_{4}\right]\left[V_{B}\right]}
\end{aligned}
$$

where:

$$
\begin{aligned}
& {\left[N_{1}\right]=\frac{1}{2(d a-b c)}\left[\begin{array}{c}
2 d a 2 d b 2 d b \\
-c a-c b-c b \\
-c a-c b-c b
\end{array}\right]\left[\begin{array}{ccc}
\cosh \left(\gamma_{m 1} d\right) & 0 & 0 \\
0 & \cosh \left(\gamma_{m 1} d\right) & 0 \\
0 & 0 & \cosh \left(\gamma_{m 1} d\right)
\end{array}\right]} \\
& +\frac{1}{2}\left[\begin{array}{ccc}
0 & 0 & 0 \\
0 & 1 & -1 \\
0 & -1 & 1
\end{array}\right]\left[\begin{array}{ccc}
\cosh \left(\gamma_{\beta} d\right) & 0 & 0 \\
0 & \cosh \left(\gamma_{\beta} d\right) & 0 \\
0 & 0 & \cosh \left(\gamma_{\beta} d\right)
\end{array}\right] \\
& +\frac{1}{2(d a-b c)}\left[\begin{array}{ccc}
-2 c b-2 d b-2 d b \\
c a & d a & d a \\
c a & d a & d a
\end{array}\right]\left[\begin{array}{ccc}
\cosh \left(\gamma_{m 2} d\right) & 0 & 0 \\
0 & \cosh \left(\gamma_{m 2} d\right) & 0 \\
0 & 0 & \cosh \left(\gamma_{m 2} d\right)
\end{array}\right] \\
& {\left[N_{2}\right]=\frac{1}{2(d a-b c)}\left[\begin{array}{l}
2 d e 2 d f 2 d f \\
-c e-c f-c f \\
-c e-c f-c f
\end{array}\right]\left[\begin{array}{ccc}
Z_{C m 1} \operatorname{senh}\left(\gamma_{m 1} d\right) & 0 & 0 \\
0 & Z_{C m 1} \operatorname{senh}\left(\gamma_{m 1} d\right) & 0 \\
0 & 0 & Z_{C m 1} \operatorname{senh}\left(\gamma_{m 1} d\right)
\end{array}\right]} \\
& +\frac{1}{2}\left[\begin{array}{ccc}
0 & 0 & 0 \\
0 & 1 & -1 \\
0 & -1 & 1
\end{array}\right]\left[\begin{array}{ccc}
Z_{C \beta} \operatorname{senh}\left(\gamma_{\beta} d\right) & 0 & 0 \\
0 & Z_{C \beta} \operatorname{senh}\left(\gamma_{\beta} d\right) & 0 \\
0 & 0 & Z_{C \beta} \operatorname{senh}\left(\gamma_{\beta} d\right)
\end{array}\right] \\
& +\frac{1}{2(d a-b c)}\left[\begin{array}{ccc}
-2 g b-2 h b-2 h b \\
g a & h a & h a \\
g a & h a & h a
\end{array}\right]\left[\begin{array}{ccc}
Z_{\mathrm{Cm} 2} \operatorname{senh}\left(\gamma_{m 2} d\right) & 0 & 0 \\
0 & Z_{\mathrm{Cm} 2} \operatorname{senh}\left(\gamma_{m 2} d\right) & 0 \\
0 & 0 & Z_{C m 2} \operatorname{senh}\left(\gamma_{m 2} d\right)
\end{array}\right] \\
& {\left[N_{3}\right]=\frac{1}{2(h e-g f)}\left[\begin{array}{l}
2 h e 2 h f 2 h f \\
-g e-g f-g f \\
-g e-g f-g f
\end{array}\right]\left[\begin{array}{ccc}
\cosh \left(\gamma_{m 1} d\right) & 0 & 0 \\
0 & \cosh \left(\gamma_{m 1} d\right) & 0 \\
0 & 0 & \cosh \left(\gamma_{m 1} d\right)
\end{array}\right]} \\
& +\frac{1}{2}\left[\begin{array}{ccc}
0 & 0 & 0 \\
0 & 1 & -1 \\
0 & -1 & 1
\end{array}\right]\left[\begin{array}{ccc}
\cosh \left(\gamma_{\beta} d\right) & 0 & 0 \\
0 & \cosh \left(\gamma_{\beta} d\right) & 0 \\
0 & 0 & \cosh \left(\gamma_{\beta} d\right)
\end{array}\right] \\
& +\frac{1}{2(h e-g f)}\left[\begin{array}{ccc}
-2 g f-2 h f-2 h f \\
g e & h e & h e \\
g e & h e & h e
\end{array}\right]\left[\begin{array}{ccc}
\cosh \left(\gamma_{m 2} d\right) & 0 & 0 \\
0 & \cosh \left(\gamma_{m 2} d\right) & 0 \\
0 & 0 & \cosh \left(\gamma_{m 2} d\right)
\end{array}\right]
\end{aligned}
$$




$$
\begin{aligned}
& {\left[N_{4}\right]=\frac{1}{2(h e-g f)}\left[\begin{array}{c}
2 h a 2 h b 2 h b \\
-g a-g b-g b \\
-g a-g b-g b
\end{array}\right]\left[\begin{array}{ccc}
\frac{1}{Z_{C m 1}} \operatorname{senh}\left(\gamma_{m 1} d\right) & 0 & 0 \\
0 & \frac{1}{Z_{C m 1}} \operatorname{senh}\left(\gamma_{m 1} d\right) & 0 \\
0 & 0 & \frac{1}{Z_{C m 1}} \operatorname{senh}\left(\gamma_{m 1} d\right)
\end{array}\right]} \\
& \times+\frac{1}{2}\left[\begin{array}{ccc}
0 & 0 & 0 \\
0 & 1 & -1 \\
0 & -1 & 1
\end{array}\right]\left[\begin{array}{cccc}
\frac{1}{Z_{C \beta}} \operatorname{senh}\left(\gamma_{\beta} d\right) & 0 & 0 \\
0 & \frac{1}{Z_{C \beta}} \operatorname{senh}\left(\gamma_{\beta} d\right) & 0 \\
& 0 & 0 & \frac{1}{Z_{C \beta}} \operatorname{senh}\left(\gamma_{\beta} d\right)
\end{array}\right] \\
& +\frac{1}{2(h e-g f)}\left[\begin{array}{ccc}
-2 c f-2 d f-2 d f \\
c e & d e & d e \\
c e & d e & d e
\end{array}\right]\left[\begin{array}{ccc}
\frac{1}{Z_{C m 2}} \operatorname{senh}\left(\gamma_{m 2} d\right) & 0 & 0 \\
0 & \frac{1}{Z_{C m 2}} \operatorname{senh}\left(\gamma_{m 2} d\right) & 0 \\
0 & 0 & \frac{1}{Z_{C m 2}} \operatorname{senh}\left(\gamma_{m 2} d\right)
\end{array}\right]
\end{aligned}
$$

In (34)-(37), the terms $\gamma_{\mathrm{m} 1}$ and $\gamma_{\mathrm{m} 2}$ are, respectively, propagation functions in modes 1 and 2 of the two-phase line, while $\mathrm{Z}_{\mathrm{Cm} 1}$ and $\mathrm{Z}_{\mathrm{Cm} 2}$ are, respectively, the characteristic impedances in modes 1 and 2 this line. Also, in (34)-(37), $\gamma_{\beta}$ and $Z_{C \beta}$ are, respectively, propagation function and characteristic impedance in $\beta$. All these elements are calculated according to three-phase line parameters.

In (34)-(37) a, b, c and d elements are written as:

$$
\begin{aligned}
& a=\frac{2 T_{11}}{\sqrt{6}}+\frac{T_{21}}{\sqrt{3}} \\
& b=\frac{T_{21}}{\sqrt{3}}-\frac{T_{11}}{\sqrt{6}} \\
& c=\frac{2 T_{12}}{\sqrt{6}}+\frac{T_{22}}{\sqrt{3}} \\
& d=\frac{T_{22}}{\sqrt{3}}-\frac{T_{12}}{\sqrt{6}}
\end{aligned}
$$

In (38)-(41), $T_{11}, T_{12}, T_{21}$ and $T_{22}$ are $\left[T_{\alpha 0}\right]$ elements obtained in (31).

In (34)-(37) e, $\mathrm{f}, \mathrm{g}$ and $\mathrm{h}$ elements are written as:

$$
\begin{gathered}
e=\frac{2 X_{11}}{\sqrt{6}}+\frac{X_{21}}{\sqrt{3}} \\
f=\frac{X_{21}}{\sqrt{3}}-\frac{X_{11}}{\sqrt{6}} \\
g=\frac{2 X_{12}}{\sqrt{6}}+\frac{X_{22}}{\sqrt{3}} \\
h=\frac{X_{22}}{\sqrt{3}}-\frac{X_{12}}{\sqrt{6}}
\end{gathered}
$$

In (42)-(45), $\mathrm{X}_{11}, \mathrm{X}_{12}, \mathrm{X}_{21}$ and $\mathrm{X}_{22}$ are $\left[\mathrm{T}_{\alpha 0}\right]^{\mathrm{t}}$ elements obtained by the inverse transpose of $\left[\mathrm{T}_{\alpha 0}\right]$.

It is observed in equations (32) and (33) that threephase line model obtained directly in phase domain is calculated according to $\left[\mathrm{N}_{1}\right],\left[\mathrm{N}_{2}\right],\left[\mathrm{N}_{3}\right]$ and $\left[\mathrm{N}_{4}\right]$ which are obtained only according to longitudinal and shunt parameters of the three-phase line, show in Figure 2.

Therefore, equations (32) and (33) represent an analytical model for three-phase lines developed directly in the phase domain.

\section{Results}

Results obtained with the model developed directly in phase domain will be compared to results obtained using a model developed modes domain [2].

The curves will be analyzed for the $200 \mathrm{~km}$ transmission line in the interval $10^{-2} \mathrm{~Hz} 10^{5} \mathrm{~Hz}$. To analyze the behavior of current curves were used the parameters of a $440 \mathrm{kV}$ three-phase line transmission line [6] (Figure 4). Classical modal method used in simulations of the line is Newton-Raphson method [2]. The line was energized by a constant tension source in two situations, the open and short circuit line [8].

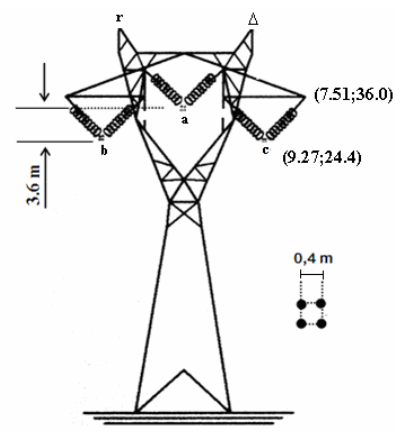

Figure 4. $440 \mathrm{kV}$ three-phase line transmission line. 


\subsection{Open circuit Response}

In this scheme a 1 p.u. step voltage is applied on phase 1 , while the phases 2 and 3 are shorted at the sending end. All the phases are open circuited at the receiving end, as described in Figure 5. Figure 6 shows the open circuit current at the sending end in phase 1.

In Figure 6, the curve 1, which represents the result obtained by using the model propose has behavior similar to curve 2, which represents the result obtained by using the classical model, for all frequency range.

\subsection{Performance Considering an Atmospheric Surge}

A frequency domain simulation considering an atmospheric impulse signal is carried out based on the aforementioned system configuration. The unitary impulse signal is modeled in the frequency domain as a normalized atmospheric impulse of $1.2 / 50 \mu \mathrm{s}$, corresponding to the technical descriptions provided by the IEC. This procedure and this wave shape are widely used in the high-voltage tests of power system devices, including insulators, capacitor banks, oxide surge arresters, and power transformers [9].

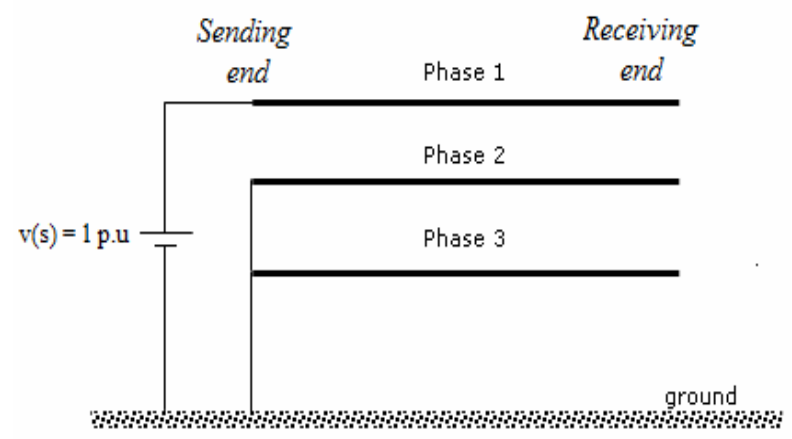

Figure 5. Open circuit test.

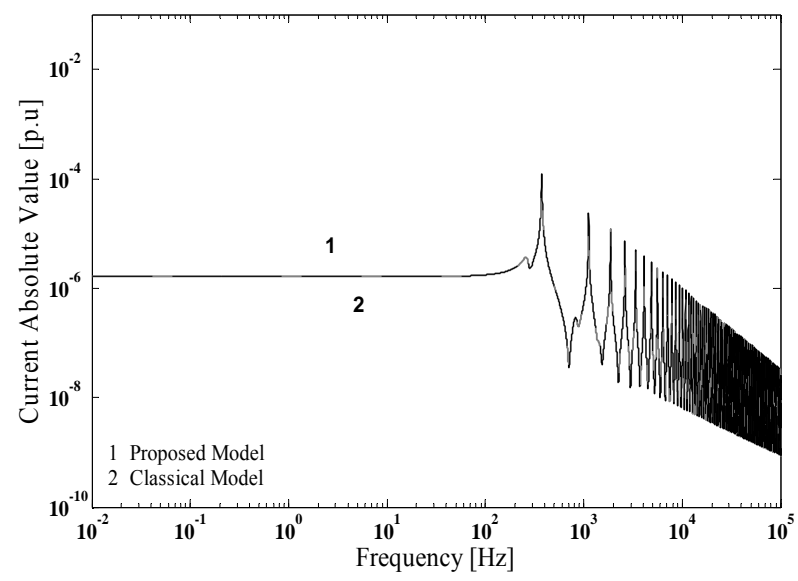

Figure 6. Open circuit response: Absolute value of the current in phase 1.

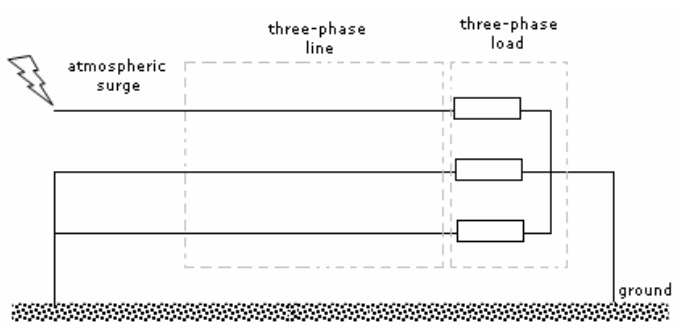

Figure 7. Atmospheric surge test.

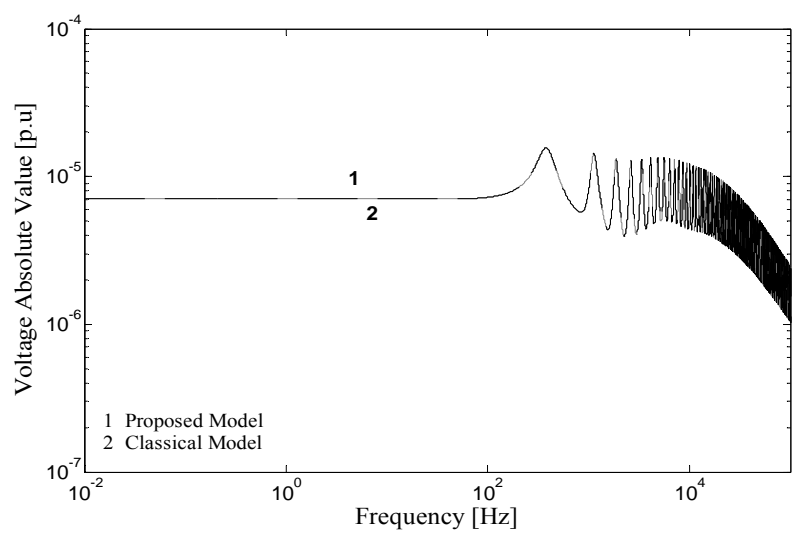

Figure 8. Atmospheric surge response: Absolute value of the voltage at the receiving end in phase 1.

The atmospheric surge is applied at the sending end of phase 1, as described in Figure 7. The voltage profile on the receiving end of the three-phase lines is shown in Figure 8.

In Figure 8 it is possible to verify that, for all frequency range, the curve 1 has behavior similar to of the curve 2 . Curve 1 shows results obtained with the model developed in phase domain (proposed model) and curve 2 shows results obtained with a model developed in modal domain (classical model).

\section{Conclusions}

This paper was presented a model developed directly in the phase domain of a non-transposed three-phase transmission line with a vertical symmetry plane.

Simulations have shown that the model responds adequately in the corresponding frequency range to maneuver and switching procedures. It was verified that for the open and short circuit test, the results were consistent across the frequency range.

Considering the equations that describe the model proposed, the currents and voltages can be obtained in any line situation analysis, these equations do not require knowledge of complex mathematical concepts (e.g. eigenvector and eigenvalue concepts) and all terms present in the equations are functions according to line parameters, which will represent the line directly in time domain. 
Therefore, the developed model can be used as an alternative model in the analysis of transient phenomenons that occur in transmission lines of electric power system.

\section{Acknowledgements}

The authors thank LETEL group - Electromagnetic Transient Laboratory - throughout complicity and collaboration and Conselho Nacional de Desenvolvimento Científico e Tecnológico (CNPQ).

\section{REFERENCES}

[1] A. B. Fernandes and W. L. A. Neves, "Phase-domain Transmission Line Models Considering Frequency Dependent Transformation Matrices," IEEE Transactions on Power Delivery, Vol. 19, No. 2, 2004, pp. 708-714. doi:10.1109/TPWRD.2003.822536

[2] L. M. Wedephol, H. V. Nguyen and G. D. Irwin, "Frequency-Dependent Transformation Matrices for Untransposed Transmission Lines Using Newton-Raphson Method," IEEE Transactions on Power Systems, Vol. 11, No. 3, 1996, pp. 1538-1546. doi:10.1109/59.535695

[3] A. Budner, "Introduction of Frequency-Dependent Line Parameters into an Electromagnetic Transients Program," IEEE Transactions on Power Apparatus and Systems, Vol. 89, No. 1, 1970, pp. 88-97.

\section{doi:10.1109/TPAS.1970.292674}

[4] L. Marti, "Low-order Approximation of Transmission line Parameters for Frequency Dependent Models," IEEE Trans. Power App. and Systems, Vol. PAS-102, No. 11, 1983, pp. 3582 - 3589. doi:10.1109/TPAS.1983.317705

[5] Chipman and A. Robert, "Teoria e Problemas de Linhas de Transmissão," Ed. McGraw-Hill from Brazil, São Paulo, 1972.

[6] S. Kurokawa, R. S. Daltin, A. J. Prado and J. Pissolato, "An Alternative Modal Representation of a Symmetrical Non-transposed Three-Phase Transmission Line," IEEE Transactions on Power Systems, Vol. 22, No. 1, 2007, pp. 500-501. doi:10.1109/TPWRS.2006.889117

[7] M. C. Tavares, J. Pissolato and C. M. Portela, "Mode Domain Multiphase Transmission Line Model - Use in Transient Studies," IEEE Transaction on Power Delivery, Vol. 14, No. 4, 1999, pp. 1533-1544. doi:10.1109/61.796251

[8] B. Gustavsen and A. Senlyen, "Combined Phase and Modal Domain Calculation of Transmission Transients Based on Vector Fitting," IEEE Transactions on Power Delivery, Vol. 13, No. 2, 1998. doi:10.1109/61.660936

[9] IEC 60060-1: 'High-voltage Test Techniques - part 1: General Definitions and Test Requirements,”Ed. 3, 2010. 